\title{
LA NATURALEZA JURÍDICO-INTERNACIONAL DE LOS ACUERDOS DE PAZ Y SUS CONSECUENCIAS EN LA IMPLEMENTACIÓN*
}

\author{
INTERNATIONAL LEGAL NATURE OF PEACE \\ AGREEMENTS AND ITS CONSEQUENCES ON \\ THEIR IMPLEMENTATION IN COLOMBIA
}

\author{
Álvaro Francisco Amaya-Villarreal** \\ VALERIA GUZMÁN-DUARTE***
}

\section{Para Citar Este Artículo / To Cite This Article}

\begin{abstract}
Amaya-Villarreal, Álvaro Francisco y Guzmán-Duarte, Valeria, La naturaleza jurídico-internacional de los Acuerdos de Paz y sus consecuencias en la implementación, 30 International Law, Revista Colombiana de Derecho Internacional, 41-60 (2017). https://doi.org/10.11144/ Javeriana.il 15-30.njia

doi:10.11144/Javeriana.i115-30.njia
\end{abstract}

* Artículo elaborado en el marco del foro organizado por la Universidad de La Sabana "International Law and Colombian Peace Agreements". Forum realizado el 8 de marzo de 2017.

** Abogado e historiador de la Pontificia Universidad Javeriana y LLM en Derecho Internacional de los Derechos Humanos de la Universidad de Essex, Reino Unido. Profesor en áreas de Derecho Internacional Público y Derechos Humanos de la Pontificia Universidad Javeriana y Universidad del Rosario. Miembro fundador de la Academia Colombiana de Derecho Internacional. Contacto: a.amaya@javeriana.edu.co

*** Abogada y politóloga de la Universidad de los Andes. Contacto: valeriaguzmand23@gmail.com 


\section{RESUMEN}

El presente artículo indaga el debate sobre la naturaleza jurídico-internacional del Acuerdo Final para la terminación del conflicto y la construcción de una paz estable y duradera y los efectos legales que ello tendría a la luz del derecho constitucional colombiano. De esta forma, explora el alcance de distintas fuentes de derecho internacional público a efectos de verificar si el mencionado Acuerdo cumple con los elementos necesarios para calificarlo como norma de derecho internacional público.

Palabras clave: Acuerdo final; derecho internacional; acuerdos especiales; Colombia 
This paper explores the discussion about the international legal status of the "Acuerdo Final para la Terminación del Conflicto y la Construcción de una Paz Estable y Duradera" and the legal effects that such status would produce under constitutional law in Colombia. Thus, it analyses the scope of public international law sources with the aim of evaluate if the beforementioned Acuerdo complies with the requierements in order to be considered a legal source under public international law.

Keywords: Final Agreetment, Public International Law; Special agreetments; Colombia

\section{SUMARIO}

INTRODUCCIÓN. I. LAS FUENTES DEL DERECHO INTERNACIONAL PÚBLICO Y EL CARÁCTER LEGAL DEL ACUERDO FINAL. A. Tratados o convenios internacionales. B. Costumbre internacional. C. Actos unilaterales de los Estados. II. LOS ACUERDOS ESPECIALES EN EL DIH Y EL CARÁCTER LEGAL DEL ACUERDOFINAL. CONCLUSIÓN. BIBLIOGRAFÍA 


\section{INTRODUCCIÓN}

Dentro de los muchos debates legales que ha suscitado el Acuerdo Final para la Terminación del Conflicto y la Construcción de una Paz Estable y Duradera (en adelante Acuerdo Final) suscrito entre el Gobierno de Colombia y la guerrilla, uno ha despertado el interés del derecho internacional público y gira en torno a determinar si dicho Acuerdo cuenta con carácter jurídico-internacional, que supondría además efectos constitucionales en Colombia.

Examinar la naturaleza jurídico-internacional del Acuerdo Final resulta relevante en aras de determinar su carácter vinculante en el ámbito internacional y con ello indagar si pueden considerarse - $\mathrm{O}$ no- como fuente de obligaciones del Estado colombiano. Igualmente, es significativo en tanto que da luces sobre cuál es el procedimiento más adecuado para su incorporación en el ordenamiento jurídico nacional.

Como lo establece Lowe, las normas del derecho internacional cubren los temas que han sido percibidos como apropiados para tener una solución legal en el plano internacional. Es un conjunto formal de prácticas y principios que surgen espontánea e inevitablemente de la coexistencia de diferentes comunidades o que resultan del esfuerzo voluntario de los Estados para cooperar en el manejo de ciertas problemáticas. ${ }^{1}$ De esta manera, desde sus días tempranos, el derecho internacional ha abordado asuntos como el hacer la guerra y la paz, la conformación de alianzas, los intercambios diplomáticos, el comercio y el retorno de delincuentes fugitivos, entre otros. Teniendo en cuenta que el Acuerdo Final firmado entre el Gobierno colombiano y la guerrilla tienen precisamente como objetivo darle fin a la guerra y construir un país en paz, y por ende involucran variados asuntos de derechos humanos y derecho internacional humanitario, resulta muy importante determinar cuál es su naturaleza dentro

1 Voughan Lowe, International Law, 34-99 (1ª ed., Oxford University Press, Oxford, 2007). 
de la esfera jurídica internacional y con ello las consecuencias de su implementación.

Ante todo es importante tener en cuenta que el derecho internacional no es un sistema unificado impuesto sobre el mundo de las relaciones internacionales y tampoco tiene un alcance determinado a priori. Así, el contraste con los ordenamientos jurídicos domésticos es grande. Shaw plantea que la verificación de una ley, en cualquier instante, dentro de los ordenamientos legales domésticos no suele ser un proceso difícil. Existe un método para establecer qué es la ley, cuál es su contenido, cómo fue creada y cómo debe interpretarse. Lo anterior, le otorga un grado de certeza al procedimiento legal, dado que es posible determinar cuándo una proposición se ha convertido en ley y los mecanismos necesarios para resolver disputas en relación con la ley son evidentes. ${ }^{2}$ Por su parte, la situación en la esfera jurídica internacional es muy distinta.

Lowe (2007) afirma que la diferencia crucial entre el derecho internacional y el derecho doméstico es que en este último el Estado es soberano. Cuenta con la denominada "soberanía interna", lo que implica que sus órganos y entidades están sujetos a la ley de aquel Estado, y únicamente a las de ese Estado. No se reconoce un gobierno superior. Mientras tanto, en el derecho internacional, no existe un cuerpo o institución legislativa con la facultad de crear leyes internacionalmente vinculantes para todos ni tampoco un sistema de cortes con jurisdicción coercitiva ante el cual los Estados puedan ser obligados a comparecer. ${ }^{3}$ De acuerdo con Shaw, esta característica es reforzada dada la naturaleza anárquica de los asuntos internacionales y el choque de soberanías. No obstante lo anterior, el derecho internacional existe, es determinable y "la mayoría de Estados cumplen con la mayoría de normas la mayoría del tiempo". En efecto, existe

2 Malcom Shaw, International Law, 65-175 (5 ed., Cambridge University Press, New York, 2003).

3 Voughan Lowe, International Law, 34-99 (1 ${ }^{\text {a }}$ ed., Oxford University Press, Oxford, 2007).

4 Malcom Shaw, International Law, 65-175 ( $5^{\mathrm{a}}$ ed., Cambridge University Press, New York, 2003). 
en el derecho internacional una serie de fuentes disponibles de las cuales se pueden extraer y analizar las normas.

Con base en estas fuentes, el presente artículo evalúa el potencial carácter jurídico internacional del Acuerdo Final, por medio de las siguientes secciones: en un primer momento, se desarrollan los elementos de fuentes de derecho internacional público y se evalúa si el Acuerdo Final cumple con ellos. Luego, se centra en el estudio de una fuente de derecho internacional específica, conocida como acuerdos especiales, con el fin de hacer la misma evaluación respecto de esta especialísima fuente de derecho internacional público.

\section{LAS FUENTES DE DERECHO INTERNACIONAL PÚBLICO Y EL CARÁCTER LEGAL DEL ACUERDO FINAL}

Si bien el artículo 38 del Estatuto de la Corte Internacional de Justicia dispone una directriz específicamente dirigida a este Tribunal, este ha sido ampliamente reconocido en la doctrina y en la práctica como un referente autorizado en materia de fuentes de derecho internacional. Dicho artículo estipula que la Corte deberá decidir los casos de su jurisdicción con base en:

1. Las convenciones internacionales, sean generales o particulares, que establecen reglas expresamente reconocidas por los Estados litigantes.

2. La costumbre internacional como prueba de una práctica generalmente aceptada como derecho.

3. Los principios generales de derecho reconocidos por las naciones civilizadas.

4. Las decisiones judiciales y las doctrinas de los publicistas de mayor competencia de las distintas naciones. ${ }^{5}$

Aun cuando el artículo 38 ha sido reconocido como referente en materia de fuentes del derecho internacional público, el lis-

5 Estatuto de la Corte Internacional de Justicia, 26 de junio de 1945, publicación oficial. 
tado en este contenido es de carácter meramente enunciativo. Por tanto, es posible hablar hoy de otras fuentes legales internacionales, como ciertas resoluciones de órganos internacionales, los principios de derecho internacional o los actos unilaterales del Estado.

En esta sección indagamos los elementos de algunas de las fuentes de derecho internacional público y revisamos si el Acuerdo Final cumple con elementos para ser considerado norma de derecho internacional público.

Tratados o convenios internacionales

Un acuerdo internacional puede ser llamado tratado, convención, convenio, carta, entre otros; pero por lo general, todos estos se subsumen en el concepto de "tratado", y el Derecho de los Tratados aplica a todos estos acuerdos. El artículo 2(1)(a) de la Convención de Viena sobre el Derecho de los Tratados de 1969 define un tratado como un "un acuerdo internacional celebrado por escrito entre Estados y regido por el derecho internacional". 6 De esta manera, un tratado internacional hace referencia a una transacción entre Estados, a la creación de acuerdos escritos, por medio de los cuales los Estados participantes se vinculan legalmente para actuar de una forma particular o para establecer determinadas relaciones entre ellos, que se rigen por el derecho internacional. Así, en un tratado internacional, se estipulan una serie de condiciones y acuerdos que obligan a las partes. ${ }^{7}$

$\mathrm{Si}$ bien el Acuerdo Final es un pacto escrito y expreso que tiene vocación de producir obligaciones vinculantes para las partes en cuestión, este carece de uno de los elementos esenciales de los tratados, a saber, la naturaleza de las partes firmantes. De acuerdo con la Convención de Viena, los tratados son acuerdos internacionales celebrados entre Estados. Los tratados se hacen en nombre de los Estados por funcionarios del gobierno

Convención de Viena sobre el Derecho de los tratados, 23 de mayo de 1969, publicación oficial.
Malcom Shaw, International Law, 88-92 (5ª ed., Cambridge University Press, New York, 2003). 
con plenos poderes para ello. El Acuerdo Final que se analiza aquí constituye un acuerdo entre el Gobierno colombiano y la guerrilla de las FARC. Siendo así, aunque una de las partes firmantes corresponde al Estado colombiano, por otro lado, las FARC, no pueden considerarse como un Estado o representante de un Estado. En este sentido, el Acuerdo Final no constituye en principio un tratado internacional.

Costumbre internacional

El artículo 38(1) del Estatuto de la Corte Internacional de Justicia (CIJ) identifica su segunda fuente formal como "costumbre internacional, como evidencia de una práctica generalmente aceptada como derecho". 8 Así, la costumbre es una práctica realizada por el Estado de forma uniforme y constante, bajo el supuesto de que esta práctica se considera obligatoria (opinio juris). ${ }^{9}$ Este segundo elemento corresponde al factor psicológico de la costumbre o lo que el artículo 38(1)(b) del Estatuto de la CIJ refiere como "aceptada como derecho". Se trata de la creencia de los Estados de que al seguir determinada práctica lo están haciendo debido a una obligación legal subyacente. Lo anterior quiere decir que, ante la ausencia de prueba de la existencia de la opinio juris, la práctica estatal permanecería sin fuerza legal vinculante, sin importar qué tan consistentemente sea seguida.

De acuerdo con lo anterior, es evidente que el Acuerdo Final suscrito entre el Gobierno colombiano y la guerrilla no se ajusta a la definición de costumbre internacional. Al no constituir estos una práctica ejercida por el Estado, de manera uniforme, constante y aceptada como derecho, no es posible situarlo dentro de esta categoría de fuentes de derecho internacional.

8 Convención de Viena sobre el derecho de los tratados, 23 de mayo de 1969, publicación oficial.

9 Voughan Lowe, International Law, 36-64 ( $1^{\mathrm{a}}$ ed., Oxford University Press, Oxford, 2007) Restatement (Third) of Foreign Relations Law of the United States § 102(2) 1987. 
En ciertas situaciones, los actos unilaterales de los Estados, incluyendo declaraciones de importantes funcionarios del Estado, tienen la posibilidad de generar obligaciones internacionales. Aunque los actos unilaterales no se consideran fuente de derecho internacional de la manera como son entendidos en el artículo 38(1) del Estatuto de la CIJ, estos pueden constituir una fuente de obligación. ${ }^{10}$ La Comisión de Derecho Internacional de las Naciones Unidas acogió una serie de recomendaciones recogidas en los informes especiales del Relator Especial, Víctor Rodríguez Cedeño, y en 2006 emitió los "Principios rectores aplicables a las declaraciones unilaterales de los Estados capaces de crear obligaciones jurídicas".

La Comisión observa que los Estados pueden resultar obligados por su comportamiento unilateral en el plano internacional, y establece que:

Unas declaraciones formuladas públicamente por las que se manifieste la voluntad de obligarse podrán surtir el efecto de crear obligaciones jurídicas. Cuando se dan las condiciones para que eso ocurra, el carácter obligatorio de tales declaraciones se funda en la buena fe [...]. ${ }^{11}$

La Comisión aclara, además, que los principios estipulados aplican únicamente sobre los actos unilaterales stricto sensu, es decir, los que adoptan la forma de declaraciones formales formuladas por un Estado con la intención de producir obligaciones en virtud del derecho internacional. Así, la Comisión y varios doctrinantes han afirmado que el subjetivo es el principal elemento de la definición adoptada, esto es, la intención del Estado que hace el acto, de crear obligaciones o producir efectos jurídicos.

Extrapolando la definición anterior al Acuerdo Final, resultaría factible considerarlo como un acto unilateral del Estado

10 Malcom Shaw, International Law, 114-116 (5 ed., Cambridge University Press, New York, 2003)

11 Comisión de Derecho Internacional de la ONU, Principios rectores aplicables a las declaraciones unilaterales de los Estados capaces de crear obligaciones jurídicas, 2006. 
colombiano en tanto que cumple con los elementos propios de él. En primer lugar, emana de una autoridad legítima con competencia sobre los temas acordados en virtud de sus funciones. En este caso, el Acuerdo Final fue firmado por el jefe de Estado y jefe de Gobierno de Colombia. Segundo, en relación con el contexto en el que se produce el acto, el Acuerdo surge dentro de un marco de una negociación legítima, un evento de conocimiento de todo el país y de muchos actores dentro de la comunidad internacional. Tercero, entraña obligaciones para el Estado colombiano ya que se enuncian en términos claros y específicos y además no se oponen en ninguna manera a alguna norma imperativa del derecho internacional.

El elemento de la voluntad del Estado de contraer obligaciones puede evidenciarse en dos instancias. Primero, en la firma misma del acuerdo, porque el Estado acepta cumplir con las obligaciones establecidas en estos y se compromete a ejecutar ciertas acciones con el objetivo de darle fin a la guerra. Segundo, el presidente Juan Manuel Santos hizo una serie de intervenciones ante los miembros de la Asamblea General de la ONU y ante el Consejo de Seguridad de esta misma organización y declaró que después de más de medio siglo de conflicto armado interno, la guerra había finalizado en Colombia con la firma del Acuerdo Final. En su declaración, mencionó que las FARC desaparecerían como grupo armado y que se reincorporarían a la sociedad para convertirse en movimiento político. Además, dijo que se acordaron medidas y programas para implementar entre el Gobierno y el grupo armado para asegurar las condiciones de paz en el país. Igualmente, estableció que el proceso se había centrado en la protección y garantía de los derechos de las víctimas y que para tal fin, se habían pactado mecanismos como la comisión de la verdad, medidas de reparación y restauración y un complejo sistema de justicia transicional. El Presidente fue enfático al afirmar que el Estado y las FARC trabajarían conjuntamente para lograr la implementación de los puntos pactados en el Acuerdo. 
En este orden de ideas, dichas declaraciones cumplen con lo establecido en el principio 6 formulado por la Comisión de Derecho Internacional (CDI) según el cual las declaraciones unilaterales podrán ser dirigidas a la comunidad internacional en su conjunto o a uno o varios Estados; en este caso, el presidente Santos se dirige a la comunidad internacional por medio de la Asamblea General de las Naciones Unidas, para manifestar la voluntad del Estado colombiano de cumplir con lo acordado con el grupo guerrillero. De esta manera, se generan obligaciones jurídicas para Colombia en el plano internacional. Ahora bien, el texto del acuerdo descrito en el acto del Presidente fue la versión anterior al plebiscito del 2 de octubre de 2016, luego del cual fue modificado. Esta circunstancia sugiere al menos la pregunta sobre si tendría que producirse una nueva declaración unilateral del Estado colombiano con relación al nuevo Acuerdo Final.

\section{LOS ACUERDOS ESPECIALES EN EL DIH Y EL CARÁCTER LEGAL DEL ACUERDO FINAL}

Con el fin de garantizar la seguridad y estabilidad jurídica a los contenidos del Acuerdo Final y con ello facilitar y asegurar su implementación y desarrollo normativo, se sugirió calificar este como acuerdo especial bajo derecho internacional humanitario (DIH). En un principio, fue estipulado en el artículo 4 del Acto Legislativo 01 del 7 de julio de 2016 que, el Acuerdo Final constituía un Acuerdo Especial en los términos del Artículo 3 común a los cuatro Convenios de Ginebra, y que una vez fuera firmado y entrara en vigor ingresaría en estricto sentido al bloque de constitucionalidad en su totalidad. Lo anterior fue determinado por las partes, partiendo de la base de que si en esencia lo que buscan los Acuerdos Especiales a la luz del artículo 3 común a los Convenios de Ginebra es humanizar la guerra, entonces, estos podían llegar a contemplar un acuerdo para poner punto final al conflicto. 
Puntualmente, el Gobierno se preguntó: “¿Si los Acuerdos buscan humanizar la guerra y por tanto lograr que cese el sufrimiento de la población, no es el fin del conflicto y un acuerdo de paz el mejor modo de lograr ese objetivo?". Esta duda fue llevada al Comité Internacional de la Cruz Roja (CICR), máxima autoridad en la materia, para que emitiera un concepto a solicitud del Gobierno nacional. En efecto, el CICR afirmó que los acuerdos especiales pueden también prever mecanismos y otras medidas concretas que faciliten las obligaciones de las partes, y, que en efecto, el artículo 3 común puede ser implementado mediante acuerdos de paz, en la medida en que estos contengan disposiciones que impliquen la entrada en vigor del DIH. ${ }^{12}$ Para el Gobierno y las FARC este concepto fue clave y decidieron pactar esa fórmula para blindar el Acuerdo Final.

No obstante, y como resultado del plebiscito del 2 de octubre de 2016, el artículo 4 del Acto Legislativo 1 de 2016 fue derogado mediante el Acto Legislativo 2 de 2017, que remplazó su texto de la siguiente manera:

En desarrollo del derecho a la paz, los contenidos del Acuerdo Final para la terminación del conflicto y la construcción de una paz estable y duradera, firmado el día 24 de noviembre de 2016, que correspondan a normas de derecho internacional humanitario o derechos fundamentales definidos en la Constitución Política y aquellos conexos con los anteriores, serán obligatoriamente parámetros de interpretación y referente de desarrollo y validez de las normas y las leyes de implementación y desarrollo del Acuerdo Final, con sujeción a las disposiciones constitucionales.

De esta manera se renunció a calificar de manera expresa en el ordenamiento constitucional el Acuerdo Final como acuerdo especial a la luz del DIH. Esta nueva fórmula no reconoce la posibilidad de que en términos del artículo 3 común a los Convenios de Ginebra, el Acuerdo Final pueda incorporarse bajo la figura de acuerdo especial como ley de la República. Por otro lado, no permite la entrada al bloque de constitucionalidad del

12 Comité Internacional de la Cruz Roja, Colombia: 10 preguntas sobre acuerdos de paz, acuerdos especiales y DIH, 27 de junio de 2016. 
Acuerdo y, como consecuencia, no se produce la incorporación del Acuerdo Final al ordenamiento jurídico nacional. Con ello, deja la implementación del Acuerdo sujeta al desarrollo legislativo correspondiente en el Congreso, que según el senador Juan Fernando Cristo, ponente del proyecto, es necesario a fin de otorgarle sustento normativo y validez jurídica a los componentes del Acuerdo.

No obstante, la discusión persistió, debido a la demanda interpuesta por el entonces Fiscal General de Nación, Eduardo Montealegre Lynnet, en marzo de 2016, en la que solicitó a la Corte Constitucional declarar el carácter de acuerdo especial del Acuerdo Final. Al respecto, en febrero de 2017 el magistrado Jorge Iván Palacio radicó ponencia en este proceso en la cual establecía que el Acuerdo Final debía ser considerado como un Acuerdo Especial a la luz del artículo 3 común a los Convenios de Ginebra. Sin embargo, no se propuso incorporar de forma automática la totalidad del Acuerdo dentro del bloque de constitucionalidad, sino únicamente aquellos aspectos que la Corte determinara que cumplían con el DIH y el Derecho Internacional de los Derechos Humanos. De haberse aprobado esta ponencia, podrían aplicarse las normas supranacionales aplicables a tratados y acuerdos especiales, a los componentes del Acuerdo que guarden relación con el DIH, por ejemplo, la dejación de las armas, las zonas de concentración, el cese bilateral, el desminado, ente otros. Sin embargo, la Corte Constitucional no resolvió de fondo la demanda interpuesta por el fiscal Montealegre y se declaró inhibida para ello por no haberse formulado un cargo de inconstitucionalidad cierto y suficiente. ${ }^{13}$

Ahora bien, a pesar de la falta de categorización formal del Acuerdo Final como acuerdo especial, vale la pena plantear una serie de preguntas al respecto, con ánimo académico. En primer lugar, si es posible considerar los Acuerdos de Paz como Acuerdos Especiales a la luz de lo establecido en el artículo 3

13 Corte Constitucional de la República de Colombia, Sala Plena, Sentencia C-171 de 2017, Expediente D-11329. Magistrado ponente: Iván Escrucería Mayolo. 
común a los Convenios de Ginebra. En la última actualización de comentarios a los Convenios de Ginebra, publicada en marzo de 2016, el CICR se pronunció sobre el concepto de Acuerdo Especial. En síntesis, el CICR afirma que un acuerdo de paz, un acuerdo de cese de hostilidades u otro similar pueden considerarse como acuerdos especiales si contienen cláusulas para crear otras obligaciones derivadas de los Convenios de Ginebra o sus protocolos adicionales. De acuerdo con el CICR, el párrafo 3 del artículo 3 común invita a las partes en un conflicto armado no internacional a realizar esfuerzos importantes, dentro de los cuales se prevé el establecer acuerdos, para aplicar las demás disposiciones de los Convenios de Ginebra que no son formalmente aplicables a este tipo de conflictos. ${ }^{14}$ Así, el artículo determina que las partes en conflicto harán lo posible por poner en vigor, mediante acuerdos especiales, la totalidad o parte de las otras disposiciones de los Convenios. Esto significa que se exhorta a que las partes dentro del conflicto acuerden conjuntos de normas más amplios con el fin de proteger a las personas que no participan o han dejado de participar en las hostilidades.

En este orden de ideas, un acuerdo especial es una figura del derecho internacional que les permite a las partes en un conflicto armado no internacional acordar obligaciones más amplias o detalladas de las que ya están contempladas en el artículo 3 común de los Convenios de Ginebra, con el propósito de proteger a la población civil y a las víctimas del conflicto. De esta manera, como bien lo aclara el CICR, un acuerdo de paz o un acuerdo de cese de hostilidades puede considerarse como acuerdo especial, siempre y cuando incluya cláusulas que creen obligaciones derivadas de los Convenios de Ginebra o de sus protocolos adicionales. ${ }^{15}$ En efecto, los acuerdos de paz que se firman con el objetivo de poner fin a las hostilidades pueden contener disposiciones derivadas de otros tratados de DIH;

14 Comité Internacional de la Cruz Roja, Comentario actualizado de los Convenios de Ginebra y sus Protocolos, marzo de 2016.

15 Comité Internacional de la Cruz Roja, ¿Qué dice el DIH sobre los acuerdos especiales en el marco de un proceso de paz?, junio de 2016. 
por ejemplo aquellas relativas a la liberación de personas capturadas o el compromiso de buscar personas desaparecidas o la concesión de amnistía a los combatientes que se hayan ceñido a las leyes de la guerra. En este sentido, si dentro de un acuerdo de paz se incorporan disposiciones derivadas del DIH que busquen implementar sus obligaciones, estos acuerdos podrán constituir acuerdos especiales conforme al artículo 3 común. Lo anterior encuentra sustento en el hecho de que las normas del DIH son la base de las obligaciones de las partes en un conflicto armado, a las que se le suma el derecho interno; no obstante, en ocasiones esto no es suficiente para regular aspectos específicos de las obligaciones y es cuando las partes suscriben acuerdos especiales para ampliar sus deberes o definir mecanismos para ejecutar responsabilidades con fines humanitarios.

Es precisamente esto lo que ocurre en Colombia con el Acuerdo Final pactado entre el Gobierno y la guerrilla. Se trata de un conjunto de disposiciones que acuerdan las partes en conflicto, muchas de las cuales surgen de obligaciones estipuladas en el DIH y el Derecho Internacional de los Derechos Humanos (DIDH).

Sin embargo, surge un segundo interrogante: ¿Es posible calificar el Acuerdo Final en su conjunto como acuerdo especial? Al respecto se pueden plantear al menos dos posturas. Por un lado, aquella que señala que no es posible que la totalidad del texto del Acuerdo Final pueda considerarse como acuerdo especial, en tanto que existen varios puntos que no guardan relación con el DIH, que es la condición sine qua non para que pueda adoptar esta naturaleza. Hay quienes opinan que si bien el Acuerdo Final contiene apartes con relación al DIH y al DIDH, esta referencia no debe tomarse como determinante del estatus jurídico del Acuerdo. ${ }^{16}$ Plantean que el Acuerdo regula cuestiones que responden más a una naturaleza interna que a una naturaleza internacional, como la reforma agraria, la incorporación de los

16 Luisa Vierucci, The Colombian Peace Agreement of 24 November 2016 and International Law: Some Preliminary Remarks (1 ${ }^{\mathrm{a}}$ ed., University of Florence, Florencia, 2017). 
miembros de la guerrilla a la vida civil, la lucha contra las drogas o la reparación de las víctimas. De esta manera, consideran que el marco legal dentro del cual se concibe el Acuerdo es el ordenamiento jurídico nacional y no el derecho internacional, por lo que este debería regularse por la Ley colombiana. ${ }^{17}$ Así, según esta postura, únicamente podría aceptarse que aquellos puntos del Acuerdo que constituyen una manera de implementar los Convenios de Ginebra, como la Jurisdicción Especial para la Paz, pueden considerarse como disposiciones estipuladas de acuerdo con el artículo 3 común. ${ }^{18}$

Por otro lado, está aquella posición que expresa que los elementos del Acuerdo Final destinados a superar las causas del conflicto armado pretenden no solo acabar con las hostilidades sino evitar que la violencia armada surja de nuevo. De esta forma, las medidas en materia de tierras o solución del asunto de las drogas ilícitas, al buscar una paz estable, estarían orientadas al fin último del DIH, es decir, a evitar el impacto humanitario que produce el conflicto armado. Por ello, el Acuerdo Final en su conjunto se podría considerar como acuerdo especial.

Ahora bien, se abre otro cuestionamiento y es si los acuerdos especiales pueden, al igual que los tratados internacionales, prevalecer sobre el derecho nacional. El CICR no zanja esta discusión, porque afirma que aunque los acuerdos especiales no tienen la misma naturaleza que un tratado internacional, "no debe recurrirse al derecho nacional para obstaculizar la aplicación de un acuerdo especial negociado de buena fe por las partes en conflicto". Sobre ello, plantea que el artículo 3 de la Convención de Viena de 1969 sobre el derecho de los Tratados es claro en virtud de que esta no aplica a los acuerdos internacionales celebrados entre Estados y otros sujetos del derecho internacional. A pesar de ello, el CICR afirma también, que "así constituyan o no tratados en virtud del derecho internacional,

17 Sobre la cuestión del estatus legal del Acuerdo Final véase L. Betancur Restrepo, The Legal Status of the Colombian Peace Agreement, AJIL Unbound, Noviembre de 2016, 188.

18 Luisa Vierucci, Applicability of the Conventions by Means of Ad Hoc Agreements, en A. Clapham, P. Gaeta, y M. Sassoli (eds.), The 1949 Geneva Conventions -A Commentary, 515-517 (Oxford University Press, Oxford, 2015). 
los acuerdos especiales concluidos entre partes en conflictos armados no internacionales, sin duda crean obligaciones en materia de derecho internacional". De hecho, varios Tribunales y autoridades internacionales han considerado acuerdos especiales como vinculantes y semejantes a un tratado (como la Comisión Internacional de Encuesta sobre Darfur; TIPY). Ahora bien, en otras ocasiones, no se les ha atribuido la misma fuerza vinculante que a un tratado y se ha buscado un respaldo de las obligaciones en el derecho internacional humanitario consuetudinario. 


\section{CONCLUSIÓN}

Pareciere que a través del Acto Legislativo 02 de 2017, el Gobierno colombiano ha optado por una fórmula sui generis, en la que se abstiene de denominar el Acuerdo Final como acuerdo especial expresamente, pero le otorga fuerza normativa a su contenido. De esta manera, es posible sugerir que la propuesta de hacer uso de la figura de acuerdo especial para dar carácter jurídico internacional al Acuerdo Final y así procurar su blindaje jurídico, enfrentó dificultades para ser legitimada y por tanto desechada por el Gobierno y la guerrilla. Igualmente, la Corte Constitucional al declararse inhibida en la demanda que pretendía se le otorgara tal categoría al Acuerdo Final, mantiene la incertidumbre sobre su naturaleza jurídico-internacional o no. Al margen de estas realidades formales, la discusión despertó un debate de profundas reflexiones alrededor del derecho internacional humanitario, en un momento en el que irónicamente se pretende dejar atrás el conflicto armado y por tanto la aplicación el DIH por sustracción de materia. Pareciera entonces que la discusión sobre la estabilidad jurídica del Acuerdo Final pasa actualmente más por el ámbito de lo político que de lo jurídico. 


\section{BIBLIOGRAFÍA}

\section{Instrumentos internacionales}

Estatuto de la Corte Internacional de Justicia, 26 de junio de 1945.

Cuatro Convenios de Ginebra de 1949

Convención de Viena sobre el Derecho de los tratados, 23 de mayo de 1969

\section{Normatividad nacional}

Acto Legislativo 01 de 2017, por medio del cual se crea un título de disposiciones transitorias de la constitución para la terminación del conflicto armado y la construcción de una paz estable y duradera y se dictan otras disposiciones, 50196 Diario Oficial, 4 de abril de 2017.

\section{Jurisprudencia internacional y nacional}

Restatement (Third) of Foreign Relations Law Of The United States § 102(2) 1987.

Corte Constitucional de la República de Colombia, Sala Plena, Sentencia C-171 de 2017. Expediente D-11329, Magistrado ponente: Iván Escrucería Mayolo.

\section{Doctrina}

Comisión de Derecho Internacional de la ONU, Principios rectores aplicables a las declaraciones unilaterales de los Estados capaces de crear obligaciones jurídicas, 2006.

Comité Internacional de la Cruz Roja, Colombia: 10 preguntas sobre acuerdos de paz, acuerdos especiales y DIH, 27 de junio de 2016.

Comité Internacional de la Cruz Roja, Comentario actualizado de los Convenios de Ginebra y sus Protocolos, marzo de 2016.

Comité Internacional de la Cruz Roja, ¿Qué dice el DIH sobre los acuerdos especiales en el marco de un proceso de paz?, junio de 2016.

Libros

Shaw, Malcolm, International Law ( $5^{\mathrm{a}}$ ed., Cambridge University Press, New York, 2003).

Vierucci, Luisa, The Colombian Peace Agreement of 24 November 2016 and Interna- 
tional Law: Some Preliminary Remarks (1 ${ }^{\mathrm{a}}$ ed., University of Florence, Florencia, 2017).

Vughan Lowe, International Law (1 ${ }^{a}$ ed., Oxford University Press, Oxford, 2007).

\section{Revistas}

Betancur Restrepo, L., The Legal Status of the Colombian Peace Agreement, AJIL Unbound, Noviembre de 2016, 188.

Vierucci, Luisa, Applicability of the Conventions by Means of Ad Hoc Agreements, en A. Clapham, P. Gaeta, y M. Sassoli, eds., The 1949 Geneva Conventions -A Commentary, 515-517 (Oxford University Press, Oxford, 2015). 